DOI: $10.2478 / \mathrm{v} 10190-010-0005-3$

\title{
CLIMATE CHANGE INFLUENCES ON ANTARCTIC BIRD POPULATIONS
}

\author{
MAŁGORZATA KORCZAK-ABSHIRE \\ Department of Antarctic Biology, Polish Academy of Sciences \\ Ustrzycka 10/12, 02-141 Warsaw, Poland \\ e-mail:korczakm@gmail.com
}

\begin{abstract}
Rapid changes in the major environmental variables like: temperature, wind and precipitation have occurred in the Antarctic region during the last 50 years. In this very sensitive region, even small changes can potentially lead to major environmental perturbations. Then the climate change poses a new challenge to the survival of Antarctic wildlife. As important bioindicators of changes in the ecosystem seabirds and their response to the climate perturbations have been recorded. Atmospheric warming and consequent changes in sea ice conditions have been hypothesized to differentially affect predator populations due to different predator life-history strategies and substantially altered krill recruitment dynamics.
\end{abstract}

KEY WORDS: climate change, sea birds, Antarctica.

Marine seabirds are some of the best studied taxa in the Southern Ocean. Much of the reasoning behind this intensive study has been that these long-lived species are assumed to integrate across space and time and as such are thought to be good indicators of ecosystem status (Trathan et al. 2007). The main changes in the distribution and abundance of marine top predators in the Antarctic in the last two centuries were caused by human sea resources over-exploitation (Croxall et al. 1992). Now, after introducing a protection of endangered species, climate change is the main influence on the bird and mammal population conditions.

Changes in climate are likely to have impacts at all trophic levels and can manifest in a variety of ways (Chambers et al. 2005). The biological response to climate change for any given species may be extremely complex and may vary between locations, between genders and between demographic categories (Stenseth et al. 
2002), depending upon where animals breed or over-winter, and how local any regional climate change is. According to Trathan et al. (2007) for seabirds, most responses will be evident as changes in: distribution, population sizes and densities, phenology, behavior community interactions, morphology or physiology and patterns of movement (migrations routes).

\section{CLIMATIC CHANGES IN THE ANTARCTIC}

All regionally specific climate factors like air temperatures, wind direction and velocity, as well as precipitation affect the structure and functioning of the ecosystem.

The temperature trends are very variable across the continent. Rapid warming has occurred over the Antarctic Peninsula, which stands out as a clear and consistent region of rapid change, whereas conditions have been much more variable in other sectors (Turner et al. 2005). The Antarctic Peninsula has experienced a major warming over the last 50 years. At Faraday/Vernadsky Stations the temperatures increased at a rate of $0.56^{\circ} \mathrm{C}$ decade ${ }^{-1}$ over the year and $1.09^{\circ} \mathrm{C}$ decade during the $^{-1}$ winter (Turner et al. 2005). Whereas mean temperature trends for the Antarctic continent, based on all the station trends, does not reflect the regional variability. Much contradictory information appears in literature. The reasons for such a situation are probably: low station density and their locations biased towards the coast, where gradients in meteorological variables are under large local influences and different data collecting methods. In 1957-1982 Antarctic temperature variations showed that the annual mean Antarctic temperature series had a positive linear trend amounting to a warming of $0.74^{\circ} \mathrm{C}$ (Raper et al. 1984). Although previous reports suggested continental warming (Raper et al. 1984, van den Broeke 2000), Doran et al. (2002) analysis of Antarctic meteorological data demonstrated a net cooling on the Antarctic continent between 1966 and 2000, particularly during summer and autumn.

However, recent data shows a strong warming in the Antarctic Peninsula (Vaughan et al. 2001, King et al. 2003) and a rapid cooling between 1986 and 2000 has been signaled in the Dry Valleys, Victoria Land, and East Antarctica (Doran et al. 2002).

The observed patterns in air temperature trends have affected the sea ice decline. Warming of both sea and air temperatures, lead to impending consequences, such as changed sea ice dynamics (Vaughan et al. 2003), including duration, thickness and extent of sea ice. There is growing evidence that the maximum extent of winter sea ice is declining (Curran et al. 2003). However, these signals are spatially and temporally variable, with some regions (such as the Ross Sea) showing recent increases in sea ice extent, while others (such as the Bellingshausen and Amundsen Seas) show decreases (Jacka and Budd 1998, Parkinson 2002, 2004). In Eastern 
Antarctica the duration of the sea ice season tended to increase by $>40$ days since the late 1970s (Parkinson 2002). Recent research suggests that sea ice extent is connected to large-scale features of the global climate system (such as the Southern Oscillation Index or the Southern Annular Mode), whereas the length of the sea ice season is connected to more regional features such as temperature (Parkinson 2004).

Seabirds show different degrees of association with sea ice (Ribic et al. 2008) and respond in contrasting ways to changes in seasonal sea ice extent according to their ecological characteristics, demographic strategies and regional distribution (Balerini et al. 2009). Reduction of winter sea ice extent can negatively affect breeding propensity and adult survival in some species, but is positively correlated to breeding performance in others (Barbraud and Weimerskirch 2001a, 2001b, Jenouvrier et al. 2006).

Changes in the sea ice conditions caused by warming in the Antarctic Peninsula region have been hypothesized to affect predator populations and have significantly altered krill recruitment dynamic.

\section{CLIMATE CHANGE INFLUENCE ON POPULATIONS OF PENGUINS}

There are 18 penguin species of the world, all live in the Southern Hemisphere. Four penguin species (the Adélie, emperor, chinstrap and gentoo) breed on the Antarctic continent. These species are now showing large changes in population tendencies. Their response to the climate change has been recorded by many authors (Wilson et al. 2001, Croxall et al. 2002, Kato et al. 2004, Hinke et al. 2007, Sander et al. 2007, Ballerini et al. 2009, Lynch et al. 2009).

Three species of pygoscelid penguins: Adélie penguin (Pygoscelis adeliae), gentoo penguin (Pygoscelis papua) and chinstrap penguin (Pygoscelis antarctica) are breeding regularly on King George Island, South Shetland Islands, Antarctica (Jabłoński 1984a, 1986). Observations of these populations have been recorded since Arctowski Station (6209'41'S and 58 $\left.28^{\prime} 10^{\prime \prime} \mathrm{W}\right)$ founding in 1977. In 1978 the number of breeding pairs of the three penguins species in the vicinity of Arctowski Station was recorded as 11 561, including 10140 nests of Adélie penguin, 638 nests of chinstrap, and 783 nests of gentoo penguin (Jabłoński 1986).

Penguin populations from the breeding areas on Admiralty Bay and King George Bay on King George Island were characterized by large fluctuations through the 30 years of observations (Croxall and Kirkwood 1979, Jabłoński 1984a, Jabłoński 1984b, Jabłoński 1986, Trivelpiece et al. 1987, Trivelpiece et al. 1990, Sierakowski 1991, Rakusa-Suszczewski and Sierakowski 1993, Ciaputa and Sierakowski 1999, Chwedorzewska and Korczak 2010). Comparison of newest data with previous 
one suggests that the current breeding Adélie and chinstrap penguins populations from King George Island are dramatically decreasing. During Polish investigation on summer season 2008/2009 in Admiralty Bay the following trend in penguin populations was observed: number of breeding birds of chinstrap penguin dropped by $51.6 \%$ and Adélie penguin dropped by $52.8 \%$ comparing to 1996 . On the other hand in the same period the gentoo penguin population seems to be stable or increasing. For example the gentoo population in Admiralty Bay has increased by 91.9\% since 1996. In the region of King George Bay the Adélie penguin population dropped by $62.4 \%$ and the gentoo penguin population has increased by $26.8 \%$ compared to 1996. It is significant that the decrease of Adélie penguins which was higher in the King George Bay area with practically no human impact as well as a smaller increase in the gentoo population there suggests that these fluctuations are probably not connected with anthropopression.

Moreover Hinke et al. 2007 study of Pygoscelis penguins from King George Island and Livingston Island shows that breeding colonies of Adélie and chinstrap penguins have declined by roughly $50 \%$ since the mid- 1970 s, and recruitment indices of Adélie penguins have declined by roughly $80 \%$ (Hinke et al. 2007). Described changes in the penguin populations are similar to the entire Western Antarctic Peninsula region (Smith et al. 1999, Forcada et al. 2006, Hinke et al. 2007, Sander et al. 2007, Carlini et al. 2009, Lynch et al. 2009).

In contrast, along the East coast of the Peninsula, and on the coast of the Antarctic continent, populations of Adélie Penguins have been growing. According to the data collected by airborne and ground census for Adélie penguin populations from Pointe Géologie Archipelago (since the 1980s), Ross Sea and Prince Olav Coast area (since the 1960s) increasing tendencies were observed (Wilson et al. 2001, Kato et al. 2004, Ainley et al. 2005, Jenouvrier et al. 2006).

Chinstrap Penguins breed at the northern region of Antarctica, mainly on the Antarctic Peninsula, and on the Antarctic islands (Shetland, Orkney and Sandwich). Industrial fisheries took over in the mid $20^{\text {th }}$ century have continued to remove enormous numbers of fish from the Southern Ocean region. Seals, whales and large fish competing with Chinstrap Penguins over the same food, disappeared due to being hunted by humans between the $19^{\text {th }}$ century and mid $20^{\text {th }}$ century. This situation allowed the chinstrap population to increase. The chinstrap penguin (Pygoscelis antarctica) is the most numerous of the pygoscelid penguins, with an estimated total population of 6.5-7.5 million pairs (Croxall et al. 1984, Woehler 1993, Williams 1995). Despite this increasing trend, a decreasing amount of sea ice in different regions over recent decades has introduced some variations in Chinstrap populations. Some Chinstrap colonies around the South Shetland and South Orkney islands have actually begun to decrease (Trathan et al. 1996, Hinke et al. 2007, Sander et al. 2007).

Gentoo Penguins (Pygoscelis papua) breed further north than any of the three other Antarctic penguin species. Their colonies are widespread and situated on the 
Antarctic Peninsula, the surrounding islands, as well as on the sub-Antarctic islands (Wilson et al. 1998, Pütz et al. 2001, Hinke et al. 2007, Carlini et al. 2009, Lescroël et al. 2009, Lynch et al. 2009, Miller et al. 2009). Data from their subAntarctic range suggest decline of their populations over the last 10-20 years at a major breeding site, Kerguelen Archipelago (Lescroël et al. 2009). Similarly to other northern populations, gentoo penguins breeding at Kerguelen exhibited winter laying, a slow provisioning rate, a slow growth rate associated with an extended rearing period, and relatively low breeding success compared to southern populations (Lescroël et al. 2009). The study also revealed interannual differences in the timing of laying and growth parameters as well as unusual sex differences in parental investment. Despite their high plasticity, there are indications that gentoo penguins at the northern edge of their range might work at the upper limit of their capacities (Lescroël et al. 2009).

The number of gentoo penguins have, in general, been decreasing almost everywhere, instead of along the coast of the northwest Antarctic Peninsula. In areas south of the South Shetlands where sea ice has recently disappeared numbers of this open-water species have been increasing (Hinke et al. 2007, Carlini 2009, Chwedorzewska and Korczak 2010).

Emperor penguins breed on fast sea ice during the Antarctic winter. Population data on them are very limited because of the inaccessibility of the breeding colonies during winter. Barbraud and Weimerskirch (2001a) study show that over the past 50 years, the population of emperor penguins (Aptenodytes forsteri) in Terre Adélie (one of the northernmost emperor penguin populations) has declined by $50 \%$. The emperor penguin population from the Riiser-Larsen Peninsula colony, was high in the mid1990's and suddenly decreased in 2000 (Kato et al. 2004). The Authors believe that a decrease in adult survival during the late 1970s is one of the reason (Barbraud and Weimerskirch 2001a). Out of all the Antarctic bird and mammal species, the emperor penguin has become the most vulnerable to the rapidly changing climate.

Generally, the responses of different predators have depended on prevailing physical conditions at the study sites (Smith et al. 1999, Wilson et al. 2001, Jenouvrier et al. 2006) and contrasting life-history strategies (Fraser et al. 1992, Croxall et al. 2002, Rombolá et al. 2003, Lynnes et al. 2004). But the crucial factors affecting all penguin population dynamics are changes in breeding success, survival, and recruitment. Sea ice is known to affect all of these factors. The fate of sea ice and its relationship to the food web holds the future of many species in Antarctica.

Reduced sea ice coverage in the Antarctic Peninsula region during winter causes consequent variability of Antarctic krill densities. Regional reduced krill abundance due to warming take place. Food webs are dominated by Antarctic krill (Euphausia superba). In particular, a strong correlations between indices of penguin and krill recruitment suggest that penguins especially in the South Shetland Islands may live under an increasingly krill-limited system that has disproportionate effect on the 
survival of juvenile birds (Hinke et al. 2007). The loss of ice connected with this event and poor recruitment of larval Antarctic krill Euphausia superba, explains the decrease in Adélie and chinstrap penguins observed there. Gentoo penguins because of their more flexible diet are not as strongly dependent on krill. Their population increase in the Antarctic Peninsula region can be caused by reduced sea ice and better conditions for this non-migratory species which remain near natal colonies year-round (Hinke et al. 2007). Fledging success has remained stable in all three species breeding colonies. The different trends in abundance and recruitment indices for each species, despite generally similar indices of summer performance, suggest that winter conditions contribute to the divergent responses among the penguins (Trathan et al. 1996, Hinke et al. 2007).

A decrease in sea ice is thought to be responsible for the observed Adélie and chinstrap Penguin population decline in the Western Antarctic Peninsula (Fraser et al. 1992). In other regions of Antarctica, the ice has either been stable or there has been an observed increase in sea ice extent (Smith and Stammerjohn 2001, Parkinson 2004). In East Antarctica and the Ross Sea area (Woelher et al. 2001, Croxall et al. 2002) Adélie penguin populations are increasing. Which correspond well when we consider the relationship: the sea ice tendencies and krill densities. But the negative effect of the extent of pack ice on penguin population were also recorded. The extensive sea-ice during winter appears to reduce subadult survival, expressed subsequently when these cohorts reach maturation (Wilson et al. 2001).

It is significant that numerous studies have now shown that there is considerable spatial and temporal variability in Adélie diet (Ainley 2002). Populations in the Scotia Sea and along the Antarctic Peninsula feed almost exclusively on E. superba (Coria et al. 1995, Trivelpiece et al. 2003, Lynnes et al. 2004), while those in the southern Ross Sea consume a mixture of fish (primarily the notothenid Pleuragramma antarcticum) and E. crystallorophias, a smaller euphausiid which replaces E. superba at higher latitudes (Ainley et al. 2003). Populations in the northern Ross Sea and along the east coast of Antarctica tend to have a mixed diet consisting of fish and E. crystallorophias when foraging in neritic waters over the continental shelf, and E. superba when foraging in pelagic waters at the shelf break (Kent et al. 1998, Clarke et al. 2002, Olmastroni et al. 2004). Short- and long-term diet studies have detected intra- and inter-annual variation in meal size and diet composition, which may be related to variability in prey availability (Green and Johnstone 1988, Lynnes et al. 2004), intra- and inter-specific competition (Lynnes et al. 2002, Ainley et al. 2004), or changes in physical or environmental features, such as the degree of sea-ice cover (Watanuki et al. 1997, Ainley et al. 1998, Rombolá et al. 2003).

The population of the large Antarctic predator - emperor penguins (Aptenodytes forsteri) over the past 50 years, has declined by $50 \%$ in Terre Adélie. The reason was a decrease in adult survival during the late 1970s due to a prolonged abnormally warm period with reduced sea-ice extent. Mortality rates increased when warm sea-surface temperatures occurred in the foraging area and when annual sea-ice 
extent was reduced. The mortality rate was higher for males than for females. In contrast with survival, emperor penguins hatched fewer eggs when winter sea-ice was extended. These results indicate strong and contrasting effects of large-scale oceanographic processes and sea-ice extent on the demography of emperor penguins, and their potential high susceptibility to climate change (Barbraud and Weimerskirch 2001a). The next result of Barbraud and Weimerskirch study was that the extent of pack ice, had two opposite effects on the demographic parameters of emperor penguins. Sea-ice extent in winter negatively affects hatching success, by increasing the distance between the colony and feeding grounds. Conversely, annual sea-ice extent positively affects adult survival by increasing food availability. Therefore there exists in emperor penguins a trade-off between the advantages and disadvantages of extensive pack ice. In population terms, the trophic advantage of extensive pack ice, by favoring higher survival and further reproduction, outmatches its physical disadvantage of reducing fecundity (Barbraud and Weimerskirch 2001a). There is also evidence of the abandonment of natal colonies among emperor penguins which was linked to acute disturbances such as mega-icebergs that preclude access to the colony (Kooyman et al. 2007, Shepherd et al. 2005).

\section{CLIMATE CHANGE INFLUENCE ON POPULATIONS OF FLYING BIRDS}

Data set for the southern hemisphere shows clearly that responses of Antarctic seabirds are opposite to those observed in the northern hemisphere and the Arctic but consistent with climatic and oceanographic changes in eastern Antarctica. Barbraud and Weimerskirch (2006) have been studied dates of first arrival and laying of first eggs over a 55-year period for the entire community of Antarctic seabirds in East Antarctica. Eight flying bird species were study: Southern fulmar (Fulmarus glacialoides), Cape petrel (Daption capense), south polar skua (Catharacta maccormicki), southern giant petrel (Macronectes giganteus), southern fulmar (Fulmarus glacialoides), Wilson's storm petrel (Oceanites oceanicus), Antarctic petrel (Thalassoica antarctica), snow petrel (Pagodroma nivea) also two penguin species: emperor penguin (Aptenodytes forsteri) and Adélie penguin (Pygosceli adeliae). The records show a general tendency toward later arrival and laying. Overall, species now arrive at their colonies 9.1 days later, on average, and lay eggs an average of 2.1 days later than in the early 1950s. These delays are linked to a decrease in sea ice extent that has occurred in eastern Antarctica, which underlies the contrasted effects of global climate change on species in Antarctica. In contrast, the only significant trend toward earlier laying was for the south polar skua (Catharacta maccormicki), which mainly predates eggs and chicks of Adélie penguins, whereas the other species forage at sea for fish, crustaceans and squid. 
This result doesn't correspond with phenological changes observed in the northern hemisphere, where increasing spring temperatures are likely to have had pronounced effects on nearly all phenophases. For birds, spring warming is likely to have increased the availability of food supplies, resulting in earlier arrival and laying dates (Crick et al. 1997). In Eastern Antarctica, where no major warming or cooling has occurred since the early $1950 \mathrm{~s}$, the large (12-20\%) reduction in sea ice extent was observed since the 1950s (Curran et al. 2003). It could be a reason of a decline in abundances of krill and other marine organisms (Loeb et al. 1997, Nicol et al. 2000, Atkinson et al. 2004), the major food resources for most Antarctic seabirds. Their decline could be a reason of observed delays in bird arrival and breeding. The second factor could be the fact that the sea ice season has been getting longer since the 1970s. The late break-up of sea ice is known to delay access to seabird colonies and food resources at sea (Gaston and Hipfner 1998, Ainley 2002).

It is interesting that the same sea-ice conditions may have different effects on the breeding performance of a species. The influence of regional sea-ice extent on a number of indices of breeding performance of an avian predator, the Snow Petrel, was examined (Barbraud and Weimerskirch 2001b). The percentage of breeding pairs was highly variable and there were fewer birds breeding when sea-ice cover was extensive during July. By contrast, overall breeding success and fledgling body condition were improved during years with extensive sea-ice cover during the preceding November and July-September. Authors suggested that the overall increase in winter sea-ice extent during the last decade appears to have resulted in an overall improvement of the quality of fledglings produced, and thus probably of future recruitment.

Little information exists for the Southern Hemisphere due to a lack of long term data sets of migrant birds. However the White-rumped Sandpiper (Calidris fuscicollis) non-breeding seemed to occur as a vagrant in South Shetlands area more often than it was previously reported (Korczak, Angiel and Wierzbicki in press). Diversified appearance pattern of White-rumped Sandpiper individuals or groups on King George Island could be a result of different food abundance as well as diversified weather conditions during austral springs and summers. The increasing number of $C$. fuscicollis individuals and longer periods of their presence during the last decade could be explained by notable climate warming in the Antarctic Peninsula region. During warmer spring and summer seasons prevailing conditions on beaches in ice free oasis on King George Island are closer than the ones around the Falkland Islands, the most common wintering area of White-rumped Sandpiper.

Recent changes in Antarctic seabird populations may reflect direct and indirect responses to regional climate change. The long-term data for Antarctic seabirds indicate that winter sea-ice has a profound influence. However, some effects are inconsistent between species and areas, some in opposite directions at different stages of breeding and life cycles, and others remain paradoxical. It is necessary to take into consideration that not just climate change has the influence on bird predator 
populations. Also human activity in the substantial mark influenced on population dynamics. In the Ross Sea area, Adélie population growth can be caused by humans eliminating one of the penguins' competitors, the minke whale. From the other side due to whale protection humpback whale populations are increasing now, competing with penguins over food in Antarctic Peninsula area. The combination of recent harvest driven changes and those caused by global warming may produce rapid shifts rather than gradual changes.

\section{CONCLUSION}

Seabirds and their response to the climate perturbations have been recorded as important bio-indicators of changes in the ecosystem. Atmospheric warming and consequent changes in sea ice conditions have been hypothesized to differentially affect predator populations due to different predator life-history strategies and substantially altered krill recruitment dynamics.

Significant alternations of populations sizes and changes of localization of breading areas have been recorded. Also different changes in tendencies toward arrival and laying dates were observed. Different food abundance as well as diversified weather conditions appearing during austral springs and summers have been postulated as a reason for more often occurring non-breeding vagrant birds.

Scientific results indicate that the same sea-ice conditions may have different effects on the breeding performances of a species. Like, for example observed general tendencies toward later arrival and laying of some flying bird species and an opposite significant earlier laying trend for other species.

Recent studies have shown that the Antarctic Circumpolar Wave and related sea-ice cover around the Antarctic continent may have a profound effect on the lower trophic levels of the marine environment. Extensive sea-ice cover enhances the survival of krill. However, the effects of sea-ice cover on top predators remain poorly understood.

\section{REFERENCES}

Ainley D.G., 2002, The Adélie Penguin: Bellwether of Climate Change, Columbia Univ. Press, New York.

Ainley D.G., Wilson P.R., Barton K.J., Ballard G., Nur N., Karl B., 1998, Diet and foraging effort of Adélie penguins in relation to pack-ice conditions in the southern Ross Sea, Polar Biol., 20, 311-319.

Ainley D., Ballard G., Barton K.J., Karl B., Rau G.H., Ribic C.A., Wilson P.R., 2003, Spatial and temporal variation of diet within a presumed metapopulation of Adélie penguins, Condor, 105, 95-106. 
Ainley D.G., Ribic C.A., Ballard G., Heath S., Garffey I., Karl B.J., Barton K.J., Wilson P.R., Webb S., 2004, Geographic structure of Adélie Penguin populations: overlap in colony-speciffc foraging areas, Ecol. Monogr., 74, 159-178.

Ainley D.G., Clarke E.D., Arrigo K.R., Fraser W.R., Kato A., Barton K.J., Wilson P.R., 2005, Decadal-scale changes in the climate and biota of the Pacific sector of the Southern Ocean, 1950s-1990s, Antarct Sci., 17, 171-182.

Atkinson A., Siegel V., Pakhomov E., Rothery P., 2004, Long-term decline in krill stock and increase in salps within the Southern Ocean, Nature, 432, 100-103.

Ballerini T., Tavecchia G., Olmastroni S., Pezzo F., Focardi S., 2009, Nonlinear effects of winter sea ice on the survival probabilities of Adélie penguins, Oecologia, 161, 253-265.

Barbraud C., Weimerskirch H., 2001a, Emperor penguins and climate change, Nature, 411, $183-186$.

Barbraud C. and Weimerskirch H., 2001b, Contrasting effects of the extent of sea-ice on the breeding performance of an Antarctic top predator, the Snow Petrel Pagodroma nivea, Journal of Avian Biology, 32, 297-302.

Barbraud C., Weimerskirch H., 2006, Antarctic birds breed later in response to climate change, Proceedings of the National Academy of Science, of the United States of America, 103(16), 6248-6251.

Carlini A.R., Coria N.R., Santos M.M., Negrete J., Juares M.A., Daneri G.A., 2009, Responses of Pygoscelis adeliae and P. papua populations to environmental changes at Isla 25 de Mayo (King George Island), Polar Biology, 32 (10), 1427-1433.

Chambers L.E., Hughes L., Weston M.A., 2005, Climate change and its impact on Australia's avifauna, Emu, 105, 1-20.

Chwedorzewska K. J. and Korczak M., 2010, Human impact upon the environment in the vicinity of Arctowski Station, King George Island, Antarctica, Polish Polar Research, 31(1), 45-60.

Ciaputa P. and Sierakowski K., 1999, Long-term population changes of Adélie, chinstrap, and gentoo penguins in the regions of SSSI No. 8 and SSSI No. 34, King George Island, Antarctica, Polish Polar Research, 20, 355-365.

Clarke J.R., Kerry K.R., Irvine L., Phillips B., 2002, Chick provisioning and breeding success of Adélie penguins at Béchervaise Island over eight successive seasons, Polar Biol., 25, 21-30.

Coria N.R., Spairani H., Vivequin S., Fontana R., 1995, Diet of Adélie penguins Pygoscelis adeliae during the post-hatching period at Esperanza Bay, Antarctica, 1987/88, Polar. Biol., 15, 415-418.

Crick H.Q.P., Dudley C., Glue D.E., Thomson D.L., 1997, UK birds are laying eggs earlier, Nature, 388, 526.

Croxall J.P., Kirkwood E.D., 1979, The distribution of penguins on the Antarctic Peninsula and islands of the Scotia Sea, British Antarctic Survey, Cambridge, 10, 1-186.

Croxall J.P., Prince P.A., Hunter I., McInnes S.J., Copestake P.G., 1984, The seabirds of the Antarctic Peninsula, islands of the Scotia Sea, and Antarctic continent between $80^{\circ} \mathrm{W}$ and $20^{\circ} \mathrm{W}$ : their status and conservation, [in:] Croxall J.P., Evans P.G.H., Schreiber R.W. (eds), Status and conservation of the world's seabirds, ICBP Technical Publication no. 2. ICBP, Cambridge, 637-666.

Croxall J. P., Callaghan T., Cervellati R. and Walton D.W.H., 1992, Southern Ocean Environmental Changes: Effects on Seabird, Seal and Whale Populations [and Discussion], Phil. Trans. R. Soc. Lond., 338, 319-328. 
Croxall J.P., Trathan P.N., Murphy E.J., 2002, Environmental change and Antarctic seabird populations, Science, 297, 1510-1514.

Curran M.A.J., Van Ommen T.D., Morgan V.I., Phillips K.L., Palmer A.S., 2003, Ice core evidence for Antarctic sea ice decline since the 1950s, Science, 302, 1203-1206.

Doran P.T., Priscu J.C., Lyons W.B., Walsh J.E., Fountain A.G., McKnight D.M., Moorhead D.L., Virginia R.A., Wall D.H., Clow G.D., Fritsen C.H., McKay C.P., Parsons A.N., 2002, Antarctic climate cooling and terrestrial ecosystem response, Nature, 415, 517-520.

Forcada J., Trathan P.N., Reid K., Murphy E.J., Croxall J.P., 2006, Contrasting population changes in sympatric penguin species in association with climate warming, Glob. Chang. Biol., 12, 411-423.

Fraser W., Trivelpiece W.Z., Ainley D.G., Trivelpiece S.G., 1992, Increases in Antarctic penguin populations: reduced competition with whales or a loss of sea ice due to environmental warming? Polar Biol., 11, 525-531.

Gaston A.J. and Hipfner M., 1998, The effect of ice conditions in northern Hudson Bay on breeding by Thick-billed Murres (Uria lomvia), Can. J. Zool., 76, 480-492.

Green K., Johnstone G.W., 1988, Changes in the diet of Adélie penguins breeding in East Antarctica, Aust. Wildl. Res., 15, 103-110.

Hinke J.T., Salwicka K., Trivelpiece S.G., Watters G.M., Trivelpiece W.Z., 2007, Divergent responses of Pygoscelis penguins reveal a common environmental driver, Oecologia, $153,845-855$.

Jabłoński B., 1984a, Distribution, numbers and breeding perforence of penguins in the region of the Admiralty Bay (King George Island, South Shetland Islands, Antarctica) in 1979/1980, Pol. Polar Res., 5, 5-16.

Jabłoński B., 1984b, Distribution and numbers of penguins in the region of King George Island (South Shetland Islands) in the breeding season 1980/1981, Pol. Polar Res., 5, $17-30$.

Jabłoński B., 1986, Distribution, abundance and biomass of a summer community of birds in the region of the Admiralty Bay (King George Islands, South Shetland Islands, Antarctica) in 1978/79, Polish Polar Research 7, 217-260.

Jacka T.H., and Budd W.F., 1998, Detection of temperature and sea-ice extent changes in the Antarctic and Southern Ocean, 1949-96, Ann. Glaciol., 27, 553-559.

Jenouvrier S., Barbraud C., Weimerskirch H., 2006, Sea ice affects the population dynamics of Adélie penguins in Terre Adélie, Polar Biol., 29, 413-423.

Kato A., Watanabe K., Naito Y., 2004, Population changes of Adélie and emperor penguins along the Prince Olav Coast and on the Riiser-Larsen Peninsula, Polar Biosci., 17, $117-122$.

Kent S., Seddon J., Roberston G., Wienecke B., 1998, Diet of Adélie penguins Pygoscelis adeliae at Shirley Island, East Antarctica, January 1992, Mar. Ornithol., 26, 7-10.

King J.C., Turner J., Marshall G.J., Connolley W.M. and Lachlan-Cope T.A., 2003, Antarctic Peninsula climate variability and its causes as revealed by analysis of instrumental records, [in:] Domack E.W., Burnett A., Leventer A., Conley P., Kirby M. and Bindschadler R., (eds), Antarctic Peninsula climate variability: a historical and paleoenvironmental perspective.

Kooyman G.L., Ainley D.G., Ballard G., Ponganis P.J., 2007, Effects of giant icebergs on two emperor penguin colonies in the Ross Sea, Antarctica, Antarct. Sci., 19, 31-38. 
Korczak M., Angiel P., Wierzbicki G., White-rumped Sandpiper (Calidris fuscicollis) as a reported bird on South Shetland Islands (Antarctica) an accidental or seasonal migration? In press.

Lescroël A., Bajzak C., Bost C.A., 2009, Breeding ecology of the gentoo penguin Pygoscelis papua at Kerguelen Archipelag, Polar Biology, 32(10), 1495-1505.

Loeb V., Siegel V., Holm-Hansen O., Hewitt R., Fraser W., Trivelpiece W., Trivelpiece S., 1997, Effects of sea-ice extent and krill or salp dominance on the Antarctic food web, Nature, 387, 897-900.

Lynch H.J., Fagan W.F., Naveen R., 2009, Population trends and reproductive success at a frequently visited penguin colony on the western Antarctic Peninsula, Polar Biol., 33(4), 493-503.

Lynnes A.S., Reid K., Croxall J.P., Trathan P.N., 2002, Conflict or co-existence? Foraging distribution and competition for prey between Adélie and chinstrap penguins, Mar. Biol. (Berl)., 141, 1165-1174.

Lynnes A.S., Reid K., Croxall J.P., 2004, Diet and reproductive success of Adélie and chinstrap penguins: linking response of predators to prey population dynamics, Polar Biol., 27, 544-554.

Miller A.K., Karnovsky N.J., Trivelpiece W.Z., 2009, Flexible foraging strategies of gentoo penguins Pygoscelis papua over 5 years in the South Shetland Islands, Antarctica, Mar. Biol., 156, 2527-2537.

Nicol S., Pauly T., Bindoff N.L., Wright S., Thiele D., Hosie G.W., Strutton P.G., Woehler E., 2000, Ocean circulation off east Antarctica affects ecosystem structure and sea-ice extent, Nature, 406, 504-507.

Olmastroni S., Pezzo F., Bisogno I., Focardi S., 2004, Interannual variation in the summer diet of Adélie penguin (Pygoscelis adeliae) at Edmonson Point, Document WG-EMM04/38, CCAMLR, Hobart, Australia

Parkinson C.L., 2002, Trends in the length of the Southern Ocean sea-ice season, 1979-1999, Ann. Glaciol., 34, 435-440.

Parkinson C.L., 2004, Southern Ocean sea ice and its wider linkages: insights revealed from models and observations, Antarctic Science, 16, 387-400.

Pütz K., Ingham R.J., Smith J.G., Croxall J.P., 2001, Population trends, breeding success and diet composition of gentoo Pygoscelis papua, magellanic Spheniscus magellanicus and rockhopper Eudyptes chrysocome penguins in the Falkland Islands, Polar Biol., 24(11), 793-807.

Rakusa-Suszczewski S. and Sierakowski K., 1993, Pinnipeds in Admiralty Bay, King George Island, South Shetlands (1988-1992), Pol. Polar Res., 14, 441-454.

Raper S.C., Wigley T.M., Jones P.D., Salinger M.J., 1984, Variations in surface air temperatures: part 3. The Antarctic, 1957-1982, Monthly Weather Review, 112, 1341-1353.

Ribic C.A., Ainley D.G., Spear L.B., 2008, Seabird associations in Pacific equatorial waters, Ibis, 139(3), 482-487.

Rombolá E., MarschoV. E., Coria N., 2003, Comparative study of the effects of late packice break-off on chinstrap and Adélie penguins' diet and reproductive success at Laurie Island, South Orkney Islands, Antarctica, Polar Biol., 26, 41-48. 
Sander M., Coelho Balbăo T., Polito M. J., Schneider Costa E. and Bertoldi Carneiro A.P., 2007, Recent decrease in chinstrap penguin (Pygoscelis antarctica) populations at two of Admiralty Bay's islets on King George Island, South Shetland Islands, Antarctica, Polar Biol., 30, 659-661.

Shepherd L.D., Millar C.D., Ballard G., Ainley D.G., Wilson P.R., Haynes G.D., Baroni C., Lambert D.M., 2005, Microevolution and megaicebergs in the Antarctic, Proc. Natl. Acad. Sci. USA, 102, 16717-16722.

Sierakowski K., 1991, Birds and mammals in the region of SSSI No. 8 in the season 1988/89 (South Shetlands, King George Island, Admiralty Bay), Polish Polar Research, 12, 25-54.

Smith R.C., Ainley D., Baker K., Domack E., Emslie S., Fraser B., Kennett J., Leventer A., Mosley-Thompson E., Stammerjohn S., Vernet M., 1999, Marine ecosystem sensitivity to climate change, Bio. Science, 49, 393-404.

Smith R.C. and Stammerjohn S. E., 2001, Variations of surface air temperature and sea ice extent in the western Antarctic Peninsula (WAP) region, Annals of Glaciology, 33, 493-500.

Stenseth N.C., Mysterud A., Ottersen G., Hurrell J.W., Chan K.S., Lima M., 2002, Ecological effects of climate fluctuations, Science, 297, 1292-1296.

Trathan P.N., Croxall J.P., Murphy E.J., 1996, Dynamics of Antarctic penguin populations in relation to inter-annual variability in sea ice distribution, Polar Biol., 16, 321-330.

Trathan P.N, Forcada J., Murphy E.J., 2007, Environmental forcing and Southern Ocean marine predator populations: effects of climate change and variability, Phil. Trans. R. Soc. B, 362, 2351-2365.

Trivelpiece W.Z., Trivelpiece S.G., Volkman N.J., 1987, Ecological separation of Adélie, gentoo and chinstrap penguins at King George Island, Antarctica, Ecology, 68, 351-361.

Trivelpiece W.Z., Trivelpiece S.G., Geupel G.R., Kjelmyr J., Volkman N.J., 1990, Adélie and chinstrap penguins: their potential as monitors of the Southern Ocean marine ecosystem, [in:] Kerry K.R., Hempel G. (eds), Ecological change and the conservation of Antarctic ecosystems, Proc 5th SCAR Symp Antarct Biol, Hobart, August-September 1988, Springer, Berlin Heidelberg New York, 191-202.

Trivelpiece W.Z., Salwicka K., Trivelpiece S.G., 2003, Diets of sympatrically breeding Adélie, gentoo and chinstrap penguins from Admiralty Bay, South Shetland Islands, Antarctica, 1981 to 2000, Document WG-EMM-03-29, CCAMLR, Hobart, Australia.

Turner J., Colwell S.R., Marshall G., Lachleton A.M., Carleton-Cope T.A., Jones P.D., Lagun V., Reid P.A., Iagovkina S., 2005, Antarctic Climate Change During the Last 50 Years, Int. J. Climatol., 25, 279-294.

van den Broeke M.R., 2000, On the Interpretation of Antarctic Temperature Trends, Journal of Climate, 13(21), 3885-3889.

Vaughan D.G., Marshall G.J., Connolley W.M.,. King J. C and Mulvaney R., 2001, Climate change: devil is in the detail, Science, 293(5536), 1777-1779.

Vaughan D.G., Marshall G.J., Connolley W.M., Parkinson C., Mulvaney R., Hodgson D.A., King J.C., Pudsey C.J., Turner J., 2003, Recent rapid regional climate warming on the Antarctic Peninsula, Clim. Change, 60, 243-274.

Watanuki Y., Kato A., Naito Y., Robertson G., Robinson S., 1997, Diving and foraging behaviour of Adélie penguins in areas with and without fast sea-ice, Polar Biol., 17, 296-304. 
Williams T.D., 1995, The penguins: Spheniscidae, Oxford University Press, Oxford.

Wilson R.P., Alvarrez B., Latorre L., Adelung D., Culik B., Bannasch R., 1998, The movements of gentoo penguins Pygoscelis papua from Ardley Island, Antarctica, Polar Biology, 19(6), 407-413.

Wilson P.R., Ainley D.G., Nur N., Jacobs S.S., Barton K.J., Ballard G., Comiso J.C., 2001, Adélie penguin population change in the Pacific sector of Antarctica: relation to sea-ice extent and the Antarctic Circumpolar Current, Mar. Ecol. Prog. Ser., 213, 301-309.

Woehler E.J., 1993, The distribution and abundance of Antarctic and Sub-Antarctic penguins, SCAR, Cambridge.

Woehler E. J., Cooper J., Croxall J.P., Fraser W.R., Kooyman G.L., Miller G.D., Nel D.C., Patterson D.L., Peter H.-U., Ribic C.A., Salwicka K., Trivelpiece W.Z., Weimerskirch H., 2001, A statistical assessment of the status and trends of Antarctic and subantarctic seabirds, Report on SCAR BBS Workshop on Southern Ocean Seabirds Populations, 43. 